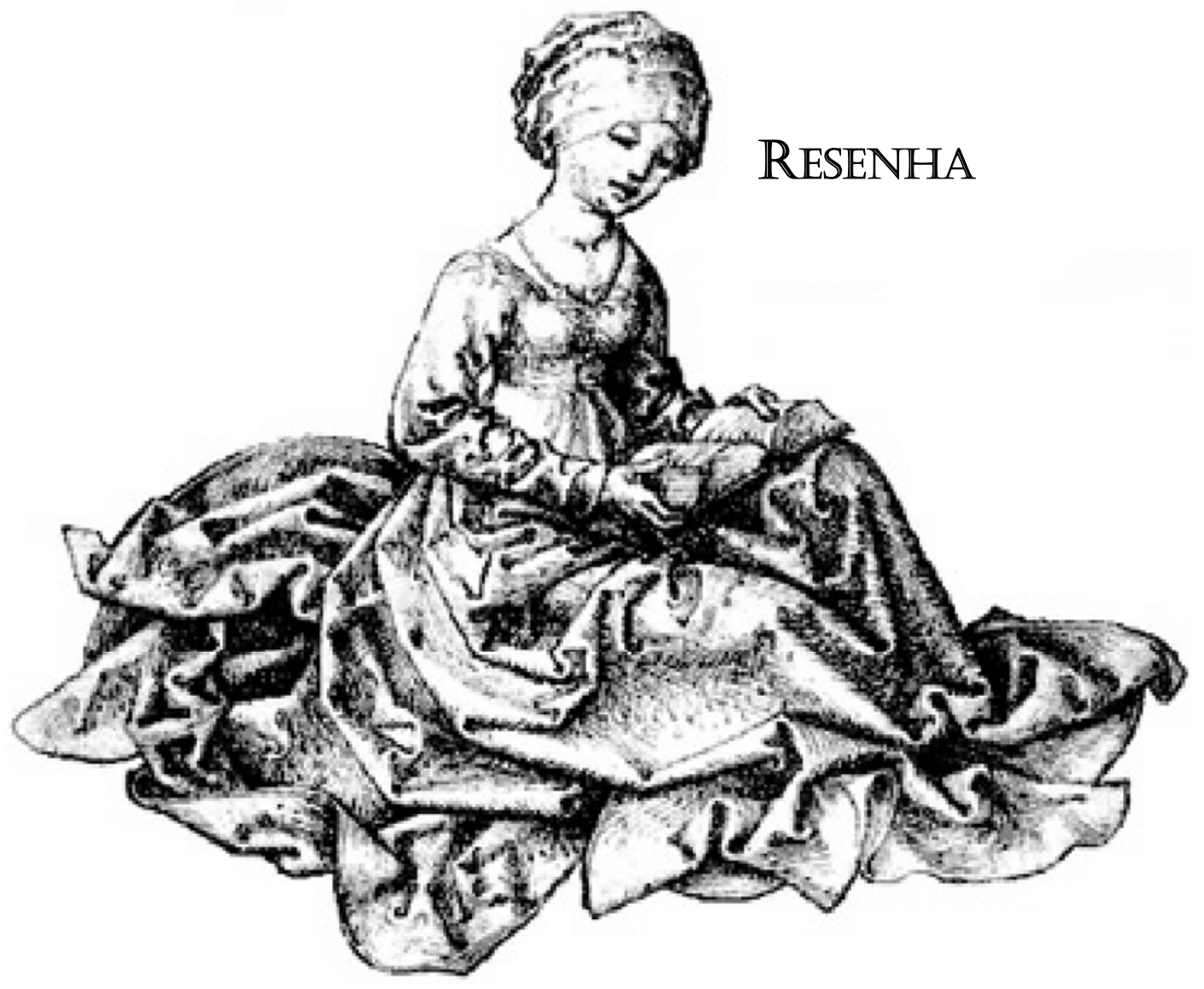





\section{DOCUMENTOS AFETIVOS: CARTAS, AMOROSIDADES E REVOLUÇÕES NO MUNDO ATLÂNTICO (1946-1960)}

\section{Elio Chaves Flores ${ }^{1}$}

CABRAL, Iva; SOUTO, Márcia; ELÍSIO, Filinto. (Orgs.). Cartas de Amílcar Cabral a Maria Helena: a outra face do homem. Lisboa: Rosa de Porcelana Editora, 2016, 398 p. [Acervo fotográfico e fac-símile da correspondência].

A expressão "mundo atlântico" está inscrita na modernidade de Áfricas, Europas e Américas. A modernidade empilhou documentos da economia política do capitalismo (Europa), da escravidão e da colonização (Américas), do tráfico diaspórico e do colonialismo (África). Tudo isso tornou possível que um jovem nascido na Guiné na década e 1920, que fez estudos básicos em Cabo Verde, nas décadas de 1930-1940, e que se encontrava em Lisboa depois da Segunda Guerra Mundial, em meio ao primeiro arrebatamento amoroso, registrasse indignação sobre os problemas raciais no Brasil da "democracia racial". Agora publicados, esses documentos afetivos - Aqui me tens - totalizam cinquenta e três cartas à colega (1946-1948), namorada (19491951) e esposa (1952-1960) Maria Helena, escritas nessas temporalidades amorosas. Na carta de 28 de agosto de 1950, Amílcar Cabral escreve a Maria Helena a sua percepção sobre o lado de cá do mundo atlântico, esse é o tema da missiva, o racismo no Brasil:

Recebi hoje tua carta, bem como o recorte do Primeiro de Janeiro, referente ao problema 'racial' no Brasil. O República já tinha publicado a notícia e também o acontecimento relativo à bailarina negra, Katherine Dunham, e ao campeão de box, Joe Louis. É mais uma prova de que a 'lepra' dos preconceitos raciais grassa por todos os lados.

[...]

Uma coisa, porém, é preciso atenção: não serão, nem poderiam sê-lo, as leis como as promulgadas no Brasil que resolverão o problema. Em muitos dos Estados Unidos da América existem leis análogas - e o negro é linchado ou escorraçado. A Constituição portuguesa é um dos mais belos documentos da igualdade dos homens, sem distinções ante o direito às benesses da civilização - e o negro em Portugal, é afastado do exército, da marinha, da Magistratura, etc. Leis do gênero da referida - quando não servem apenas para

\footnotetext{
${ }^{1}$ Doutor em História pela Universidade Federal Fluminense. Professor Associado do Departamento de História e Docente Permanente dos Programas de Pós-Graduação em História e Direitos Humanos da Universidade Federal da Paraíba. Pesquisador do CNPq - PQ-2 (Área de História Moderna e Contemporânea). E-Mail: <eliochavesflores@gmail.com>.
} 
'deitar poeira nos olhos', não conseguem mais do que amedrontar os racistas menos audaciosos ou menos poderosos, economicamente. Outras serão as que hão de extirpar de vez e para sempre o preconceito - e essas terão de corresponder a uma alteração profunda do complexo econômico-social do Mundo, base, afinal, dos preconceitos. Por isso que essas leis - levarão o seu tempo, mas hão de ser realidade - não interessarão apenas aos Negros: interessam a todos os Homens. (p. 312-313)

A carta de Amílcar é, a rigor, uma "carta pública", pois de íntima tem apenas o vocativo da amada, depois da data, "Lena". Amílcar cita várias vezes o antropólogo norte-americano Alfred Métraux ao tecer críticas aos eventos racistas no Brasil contra Katherine Dunham e Joe Louis que foram proibidos de se hospedar num hotel supostamente apenas para brancos na cidade de São Paulo². Para Métraux, o racismo era um "mito novo", justamente dos séculos da modernidade atlântica e que, para ele, talvez não sobrevivesse "à grande revolução da nossa época" - as sociedades contemporâneas que acabavam de inventar os direitos humanos. Amílcar também cita e destaca estudos da UNESCO/ ONU assinados por cientistas de vários países do mundo sobre as "diferenças" e a "história cultural" dos grupos humanos: "Os fatores que tiveram papel preponderante na evolução intelectual do homem são a sua faculdade de aprender e a sua plasticidade. Esta dupla aptidão é o apanágio de todos os seres humanos". Amílcar parece estar ciente de que o racismo é mito novo, da ordem capitalista e, mesmo do lado de cá do Atlântico, para superá-lo, haveria de se gestar "uma alteração profunda do complexo econômico-social do Mundo". Nem Amílcar nem Maria Helena que se enfiaram de corpo e alma nas revoluções africanas e contra o regime racista português de Salazar, suportariam o "dogma racial" nos exílios da Guiné-Conacry e do Marrocos.

Desde que Amílcar Cabral e Maria Helena se conheceram a "linha de cor", inexistente para a amizade, parece que acaba por condicionar as relações familiares $e$ as sociabilidades acadêmicas. Se na primeira carta (07 out. 1946) Amílcar se despedia como "colega ente amigo", o namoro assumido no ano de 1948 informa uma poética de amorosidades que precisa enfrentar o dogma racial. Na carta de 25 de abril de 1948, Amílcar lamenta a "falsidade de preconceitos nascidos de condições criadas pelo próprio homem, da teimosia (cega, aliás) num erro que hoje, dentro de limitadíssimas oportunidades, é denunciado pelas mais palpitantes manifestações das realidades, realidades que a Vida patenteia e a Ciência demonstra" (25 abr. 1948, p. 91). Pelos argumentos da paixão e pelo que se dizia de sua "africanidade", Amílcar se

\footnotetext{
${ }^{2}$ A antropóloga norte-americana Irene Diggs também foi discriminada num hotel do Rio Janeiro, por essa mesma época. Alguns casos "internacionais" repercutiam na imprensa, mas as práticas racistas institucionais e nos estabelecimentos comerciais, clubes e escolas eram diárias assim como a ausência da população negra do processo político brasileiro. Para essa discussão no contexto 1945-1960, ver: NASCIMENTO, Elisa Larkin. O sortilégio da cor: identidade, raça e gênero no Brasil. São Paulo: Selo Negro, 2003, p. 221-280.
} 
sente interpelado a se posicionar etnicamente e a se universalizar na condição humana.

Não sabem (eu gostaria de poder dizer-lhes) que sei que sou negro, isto é, que não sou caucásico ou mongoloide, mas que entre estas três raças existem diferenças apenas na cor da pele e em alguns traços fisionômicos; que tu sabes que sou negro $e$, mais do isso, que não é na cor da pele que reside o valor de um homem ou as características que poderão denunciar sua superioridade ou inferioridade perante os outros indivíduos.

Não sabem, Lena, quando dizem "Ela não aguenta", que na realidade não tens nada que aguentar, a não ser, do meu lado, algum passageiro dissabor que naturalmente te adviria de qualquer homem, e, do lado dos descontentes, uma incompreensão facilmente destrutível, filha, aliás, da ignorância e da cegueira causadas por infundamentados preconceitos; que o teu amor por mim não é um amor de mártir ou de sacrificada, mas, sim, o amor de uma Mulher por um Homem, amor que dignifica e eleva. Eu gostaria de dizer-lhes, Lena querida, que a "linha de cor" é um mito que, felizmente, a Humanidade, sempre progressiva, vai afastando do seu seio, semelhantemente ao que sucedeu a muitos outros mitos. (25 abr. 1948, p. 91)

Isso não é tudo. Amílcar precisa responder a uma questão ainda mais complexa, pois se refere à reprodução social da vida. É que o dogma racial se antecipa ao próprio evento social: "Que será dela quando tiver um filho" - negro, moreno ou mulato, nas expressões lisboetas. Lembremo-nos de Fanon: um negro castrado não é problema; a negrura estéril é utopia da brancura. A resposta que Amílcar deseja que Maria Helena distribua a esse tipo abjeto de constrangimento racial é mundana: "Não sabem, Lena, que à pergunta 'Que será dela quando tiver um filho', tu poderás responder, muito singelamente que serás uma Mãe. Mas uma mãe consciente da sua missão, integrada nos problemas da Vida - e que saberá preparar, no Mundo e para o Mundo, os seus filhos" (25 abr. 1948, p. 91).

Noutra carta, do dia 20 de agosto do mesmo ano, Amílcar deixa transparecer na narrativa certo aborrecimento sobre a mesma questão que aparece reiterada na correspondência de Maria Helena, "às pessoas que te dizem coisas mirabolantes por causa da cor da minha pele". Ele reitera que "o mito das raças é apenas um mito" e, taxativo, escreve: "Desde que sejamos absolutamente conscientes da nossa posição dentro do sério problema da nossa vida" (20 ago. 1948, p. 135). Essa longa carta, carregada de tensão e desejo, também define a confissão do "chamamento africano", a justificativa para o retorno ao continente de origem: "Mas tu sabes, como eu, quais as forças que me chamam pra a África, forças a que não resistirei, porque seria trair- 
me, trair a própria vida". Amílcar repassa para Maria Helena as contingências africanas e o faz na estilística da verve colonial, como se voltasse como herói civilizador, para "lá, onde pouquíssimo ou nada ainda se fez"; ou, "lá, onde a Técnica e a Ciência ainda são sombras"; ou, "lá, onde a vida me chama". Trata-se de uma decisão que é comunicada à luz dos eventos relacionais envoltos na subjetividade da linha de cor. Assim foi narrado: "Hoje, já que as circunstâncias mo exigem, quero dizer-te que, se totalmente impossível, tu não me acompanharás. Mas eu tenho de ir. Acabado o curso, eu só ficarei na metrópole, se de todo não puder seguir para África". Depois, passa a explicar o sentido dessa decisão: "Não conto viver toda a minha vida lá, nem espero viver no sertão, longe dos grandes centros [que designou antes como cidades progressivas e belas do litoral]. Conto apenas viver parte da minha vida em África e dar, com toda a boa vontade de que for capaz, em todo o amor imenso que em anima, o meu esforço no sentido de fazer alguma coisa pelas gentes africanas, pelos homens, afinal". O final do parágrafo é denotativo de um manifesto: "Quero dizer: subordino-me conscientemente a esta contingência da vida: tenho de ir para África". A leitura dos últimos dois parágrafos da carta permitem adjetivar esse manifesto de amoroso: "E viverão juntos [os dois enamorados] na terra onde a vida lhes oferece maiores horizontes no sentido de serem úteis à Humanidade. E creio que tu concordas comigo que esse local, para nós e porque eu sou um desses indivíduos, deve ser a África". Ao finalizar, duas verdades emolduram a missiva: "uma, é que tenho de ir para a África; outra, Lena, a outra é esta: Eu amo-te" (20 ago. 1948, p. 137-138). Nas cartas seguintes, Amílcar reconhece o tormento, a tensão e a necessidade da "consciência coletiva vencer a individual". Na carta de 26 de agosto ocorre a citação da resposta de Maria Helena: "resolvi deixar tudo para te ajudar e seguir-te" (26 ago. 1948, p. 175). É vida que segue ${ }^{3}$.

$\mathrm{Na}$ carta de 23 de agosto de 1950, uma semana antes da referida carta em relação aos eventos raciais no Brasil, Amílcar narra ironicamente o caráter burguês do bairro lisboeta onde estava residindo. O tropos da ironia para vituperar a classe burguesa será uma das expressividades de Amílcar. Ele informa que fixou residência à Av. Casal Ribeiro, num meio termo entre os bairros de Alcântara e Bairro Azul. Dizia que mais abaixo se encontravam Casal Ventoso e a Fonte Santa "e todas as demais imundícies que a injustiça social criou e alimenta". A pobreza ao longe e o modo de vida burguês na sua proximidade:

Casas características nitidamente princípio do século, grandes prédios em linha impecável, esta Avenida é na realidade

\footnotetext{
${ }^{3}$ A última carta de agosto é um relato "historiográfico" dos acontecimentos da África do Sul e da institucionalização do regime de segregação racial com a vitória do Dr. Malan, adepto do fascismo europeu, nas eleições de 1948. Amílcar anota o aspecto positivo de alguns casamentos interraciais na África do Sul (29 ago. 1948 p. 193-195). Em setembro vai para Coimbra e se encanta com a cidade, onde "sente-se toda a alma portuguesa" (12 set. 1948, p. 231). O ano de 1948 contém o maior número de correspondência: 31 cartas. Não foram escritas cartas no ano de 1949, mas aparecem três sonetos, dois dedicados a Maria Helena e um para a mãe, Iva Évora. Em abril de 1950, carta enigmática sobre a morte, onde Amílcar pensa duas mortes, a vulgar, "cessação do fenômeno vital", e a outra, uma espécie de "morte social" (p. 275-278). Na carta de 18 ago. 1950 Amílcar estuda o "africanista" Maurice Delafosse e o poeta negro cubano Nicolás Guillén (p. 302-304).
} 
interessante, mas o ar que se respira é demasiadamente burguês para nos deixar saborear a beleza das suas árvores centrais. Sim, demasiadamente burguês. Ali, defronte, as janelas eternamente fechadas: a 'madame' está na praia, como não podia deixar de ser. À tarde, meninas anêmicas e olheirentas penduram-se à janela, na linha dos cabelos propositadamente desprendidos atiram a isca de um olhar à Dorothy, condimentado pelo batom berrante. A mamã, rechonchuda e metafísica, de vez em quando vem à janela, observa a 'pesca' e palita os dentes, ruminando os detritos do 'bombom' que o papá-dinheirudo ofereceu, certamente uma compensação da última façanha extralar ou intracabret. (23 ago. 1950, p. 307)

Esse olhar crítico à cultura burguesa - às amorosidades burguesas - ironizada em 1950, ganha ares de indignação na única carta do início de 1951, na qual Amílcar se insurge contra as comemorações cristãs de passagens do ano: "O que espanta nesta decantada Civilização Cristã - é o cinismo comum às manifestações mais vulgares. Um cinismo tremendamente hipócrita, uma hipocrisia tremendamente cínica. Feliz Ano Novo" (03 jan. 1951, p. 329-330).

Amílcar Lopes Cabral (1924-1973) e Maria Helena de Ataíde Vilhena Rodrigues (1927-2005) se casaram no dia 21 de dezembro de 1951, afirmando um namoro interracial começado no Instituto Superior de Agronomia, quando eram colegas de faculdade, desde o ano de 1946, numa Lisboa salazarista e ainda "metrópole" de colônias portuguesas em África. Amílcar Cabral era filho de Juvenal Cabral e de Iva Pinhel Évora, ambos nascidos em Cabo Verde e que se encontraram na Guiné no início da década de 1920. A Guiné propiciou trabalho a Juvenal que se tornou funcionário administrativo, professor e comerciante. Sabe-se que Iva Évora chegou à Guiné aos 29 anos com um filho e, em seguida à relação amorosa com Juvenal, deu à luz ao segundo filho, Amílcar, no dia 12 de setembro de 1924, em Bafatá, na região central da Guiné. Maria Helena era filha de Joaquim Rodrigues e Carlota Ataíde Vilhena, nascidos e radicados no norte de Portugal. Carlota Ataíde deu à luz a Maria Helena em Chaves - Casas Novas, no ano de 1927. O pai de Maria Helena era capitão médico do exército colonial e há notícia de que foi gravemente mutilado numa das campanhas da África.

Para nós, brasileiros, que a cada três frases, pelo menos numa louvamo-nos como agentes das mestiçagens modernas, mas pouco toleramos amores entre homens negros e mulheres brancas, o conteúdo epistolar desses "documentos afetivos" - as cartas de Amílcar Cabral a Maria Helena - escritos na temporalidade 1946-1960 podem inspirar algumas reflexões sobre os casamentos interraciais e seus desdobramentos político-afetivos no mundo atlântico contemporâneo, isto é, a segunda metade do século XX. Talvez seja preciso concordar com Frantz Fanon que, em Pele Negra, Máscaras Brancas (1952), defendeu a ideia, num capítulo seminal, de que "é preciso falar mais longamente das relações possíveis entre o negro e a branca". 
O primeiro semestre de 1952 foi de preparativos para a viagem de retorno à África. No mês de setembro acontece a viagem. Em carta escrita a bordo da embarcação, "Atlântico, a 12 horas de Cabo Verde, em 17/9/52", Amílcar se prepara para rever Cabo Verde e, depois, chegar à Guiné, destino que aguardará, também, Maria Helena. Essa carta é expressiva do que estamos chamando "mundo atlântico". Embebido pela viagem, Amílcar observa para Maria Helena: "Hás de notar que o movimento constante do mar é o reflexo de um exemplo de movimento constante de tudo quanto existe". Nesse estado de espírito, de rever Cabo Verde e, em seguida, rever Iva, a mãe, na Guiné, sabe-se da gravidez da Maria Helena: "Porque será que eu já não sei pensar a Iva sem pensar-te?". Os planos nessa África atlântica não cessam e se a vida e o trabalho não vingarem na Guiné deveriam "abalar para Angola". O Atlântico narrado por Amílcar não é o da Grande Travessia - a trágica Middle Passage - dos negreiros da modernidade atlântica, esse Atlântico "amilcariano" é uma espécie de passagem da promissão, uma vida adulta em África que se pretendia plena.

O mar, sempre em movimento, é um manto azul, salpicado de branco. Pequenas vagas que se formam e se desfazem no próprio seio do mar. Espumas. Um cardume-bando de peixes voadores que se assustou com o monstro do ferro, e levantou voo. Ali, à esquerda, há uma estrada de prata levando ao horizonte: o reflexo do sol no mar. A conga continua, dançando o navio ao som da sua música íntima e monótona: o motor que geme. Eu, aqui, esperançoso e esperançado, escrevendo para ti, falando contigo. Ouvirá o que não digo. Sentirás o que sinto. [...] Eu incompleto, chegando. (17 set. 1952, p. 337-39)

Na carta do dia 24 de setembro, na Guiné, Amílcar informa sobre o trabalho, a casa, a mobília, a granja, o emprego e os preparativos para a viagem e a chegada de Maria Helena. Apresenta a Guiné como projeção de africanidade emancipada: "A natureza aqui, apesar de tudo quanto opiniões metafísicas podem apontar, convida ao trabalho e à conquista no sentido da 'vivificação da vida'. Se alguma certeza eu tenho - oh, se tenho certezas! - é a de que gostarás disto. Da terra e dos povos, das coisas e das gentes" (24 set. 1952, p. 348).

Não é possível saber da chegada de Maria Helena, o nascimento da primeira filha e os seus desdobramentos pela ausência de cartas, apenas uma no ano de 1953 e nenhuma no ano de 1954. Mas no ano de 1955 veremos Amílcar em viagem para São Tomé e depois para Angola. Decepciona-se com Luanda e o racismo intrínseco do fato colonial - "Isto de Luanda que estou a conhecer", dirá consternado, "é das coisas mais miseráveis que imaginar se pode em matéria de ambiente colonial". Amílcar conta o que seus olhos avistam e compara realidades coloniais africanas. Trata-se de uma visada sociológica impressionista: 
Há muitos prédios em construção, é certo, mas que valem os prédios, se os homens 'vivem' deploravelmente? Além disso, como cidade, coitadinha de Luanda aos olhos de Dakar, por exemplo. E coitadinhos dos indígenas destas paragens, aos olhos da gente da Guiné, sim, da Guiné dita portuguesa. Uma miséria, Lena. Só para pensares, fica sabendo que aqui, os choferes de táxi, os criados de hotel, restaurantes e cafés, etc. a raia miúda da sociedade é constituída por europeus. Calcularás por certo quais as posições $e$ as situações que restam (mas o que poderá restar?) para os africanos. Miséria de todos os tamanhos. Para brancos e pretos. Racismo do mais sujo, com sorriso nos lábios, só para os pretos. Enjoado, Lena. Mas a esperança e a certeza de que afora de tudo, o mundo marcha. Há de caminhar para a redenção na terra destes seres que por aqui vegetam e que são homens de coração e de cabeça.

[...]

Passam crianças pretas sujas, mal vestidas. Parecem negros tristes e sem esperança. Passam brancos ricos, bem postos, de espada, e também brancos miseráveis. Eu penso em ti e na Mariva. (30 ago. 1955, p. 365)

São nas cartas de 1955 que, ao final, Amílcar passa a se referir, também, a Mariva - Iva Maria, a primeira filha. Parece aumentar a recorrência à "linha de cor". Nesse caso, a linha de cor, sofisticada na metrópole e na academia, salta aos olhos no espaço colonial: "Passam negros tristes e sem esperança. Passam brancos ricos, bem postos, de espada, e também brancos miseráveis. Eu penso em ti e na Mariva". Pensar "raça" com Maria Helena e Mariva é universalizar a si mesmo, mas pensar "classe" amedronta o futuro. Vide que, aqui, é a "linha de classe" - ricos e pobres que divide também os brancos. A experiência Angola/ Luanda fixa uma ambiguidade amilcariana que era apenas verve quando glosa do bairro burguês lisboeta da carta de 23 de agosto de 1950. Agora ele começa a trabalhar nessa dimensão: raça $e$ classe, isto é, o fato colonial. Nas cartas seguintes, em que conhece outras cidades angolanas, Amílcar anuncia uma posição: "Lobito e Benguela são razoáveis. Mas a miséria continua. Miséria contra a qual hei de lutar" (01 set. 1955, p. 369).

$\mathrm{Na}$ carta de 10 de outubro de 1955, escrita em Catumbela, próxima de Lobito, Amílcar fala entusiasmado da leitura de Jorge Amado. Recheados na carta, copiados entre aspas, constam vários trechos da obra, mas não se menciona o título. Amílcar apenas diz: "Vou no $2 .^{\circ}$ volume e do primeiro vou transcrever-te umas passagens, belas de verdade pela poesia que encerram". Essa pista leva à trilogia, Subterrâneos da Liberdade (São Paulo, Livraria Martins Editora, 1954) ${ }^{4}$. As passagens são aquelas

\footnotetext{
${ }^{4}$ Os volumes são: Os ásperos tempos (1. $\left.{ }^{\circ}\right)$, Agonia da noite $\left(2 .^{\circ}\right)$ e A luz do túnel $\left(3 .^{\circ}\right)$. As citações que Amílcar envia para Maria Helena são do primeiro. Publicados em São Paulo, pela Livraria Martins Editora, a trilogia Os Subterrâneos da Liberdade ficcionaliza o Estado Novo (1937-1945) em três
} SAECULUM - ReVISTA DE História [36]; João Pessoa, jan./jun. 2017. 
dos enamorados, João e Mariana, operários que também se casam "por uma vida melhor". Amílcar se inspira em várias literaturas e não seria exagero se falar de um Atlântico das letras. A prosa engajada de Jorge Amado parece empolgar o missivista para o advento da luta revolucionária e, ele mesmo, vê analogias entre a história de amor, ficcional do lado de cá, mas realista do lado de lá: Amílcar e Maria Helena. O primeiro volume, Os Ásperos Tempos, recebe um tratamento de poética de amorosidade à primeira leitura. Amílcar lê o Brasil da "democracia racial" pela narrativa de Amado:

\begin{abstract}
Operários e camponeses, 'coronéis' e banqueiros, luta, flor. Luta subterrânea, na legalidade e na ilegalidade, buscando em cada gesto, em cada pensamento, a estrela que a penumbra não pode esconder, gerando sob e sobre a lama dum presente de crianças famintas, o porvir de todos os homens. A hipocrisia e o cinismo desenfreados, o interesse, o estômago dominando o coração e o cérebro, a lealdade mais bela, a solidariedade transformada em atos vividos em cada instante, o desinteresse pessoal numa luta impessoal mas coletiva. E sobre esse mundo brasileiro de 37 a 40 [19371940], a luz do luar e a luz do sol, do luar do amor e da esperança num céu grávido de estrelas, do sol nascendo da terra, das entranhas da terra, do coração dos homens e das mulheres que lutam, do olho simples e interrogativo das crianças desamparadas. O amparo nascendo do desamparo, a certeza gerada da incerteza, a luz brotando da escuridão. Só o amor, esse é o livro de Jorge Amado. Um livro dos homens, um livro para nós todos, na imensidão do seu amor e da sua esperança. Da sua certeza. (10 out. 1955, p. 373-374)
\end{abstract}

Pode ser que desse "céu grávido de estrelas", nos dois lados do Atlântico, nasça algo parecido com a revolução da justiça e da igualdade. Na carta seguinte, Amílcar se acha "um pouco gongórico", pois na medida em que se enfia no "sertão" angolano, mais necessidade de mudança ele sente para a África: "Campos de sisal por todo o lado. Nem uma parte da terra para o indígena cultivar. Exploração dos diabos. O que vale e consola e anima é que isso tudo vai mudar, vai acabar - oh se vai! - para a ressurreição da vida nestas paragens" (31 out. 1955, p. 378). Entretanto,

momentos, a partir da "voz" de um membro do Partido Comunista Brasileiro: a instauração da ditadura; a greve dos estivadores do porto de Santos; e, a perseguição aos comunistas. A edição mais recente da trilogia, no formato original, isto é, em três volumes veio a lume também em São Paulo (Companhia das Letras, 2011). Parece provável que Amílcar tenha adquirido a obra de Jorge Amado em Luanda, pois essa disponibilidade da literatura brasileira em Angola vinha desde os primeiros modernistas. Conferir: MADRUGA, Elisalva. Nas trilhas da descoberta: a repercussão do modernismo brasileiro na literatura angolana. João Pessoa: Ed. Universitária/ UFPB, 1998. 
dois anos depois, as vicissitudes econômicas do cotidiano, os problemas de saúde de Maria Helena e os seguidos deslocamentos pela Guiné, incitam uma frase lapidar, quase como súplica: "Que haja a compreensão e a paz racional que é a única mesologia adequada às nossas consciências" (21 out. 1957, p. 387).

A última carta é de 1960 e trata da guinada revolucionária. Desse lapso epistolar de dois anos o leitor nada saberá. A vida pública e a impossibilidade de servir ao Estado salazarista e aos empreendimentos coloniais parecem "apressar" uma possibilidade que vinha desde 1955 - "Não renuncio seja ao que for, mas penso que se impõe traçar um caminho seguro". Escrita de Paris, Amílcar está imerso nas atividades revolucionárias. O plano está traçado: "Tenho na algibeira a passagem para a viagem definitiva. Tenho também a ordem das passagens para ti e para Mariva, que ficarão aqui depositadas em teu nome e à tua disposição". Várias recomendações são elencadas para Maria Helena tomar providências: a papelada $e$ os livros deveriam ser enviados para Dakar - Senegal; vender a mobília da casa e o carro; levar apenas as roupas e as coisas pessoais necessárias; transferir o dinheiro $e$ economias para Londres; arrumar escola para Mariva; ajudar as mães de cada um, Carlota e Iva; ordens aos companheiros, resolver casos de hipoteca e cooperativa; enfim, "tudo o resto, inclusive o gato Mico". O término da carta indica a "nova" vida, a vida revolucionada e pela revolução: "Por hoje, paro aqui. Cheio de saudades. Talvez de ansiedade também. Mas cheio de esperanças no futuro, na vida que vamos construir. E a certeza, a consciência, a alegria de que esta carta é talvez a mais bela carta de amor que já te escrevi" (30 abr. 1960, 391-394). Ainda em 1960: Maria Helena e Mariva ficam oito meses em Paris. Amílcar Cabral adota o nome da clandestinidade, Abel Djassi. O decorrer do ano de 1960 é vida em profusão: Amílcar/Abel escreve ensaio sobre o colonialismo português; organiza quadros $e$ escola de formação revolucionária na Guiné-Conacry; vai à China comunista; tornase a principal liderança do PAIGC - Partido Africano da Independência da Guiné e Cabo Verde; no mês de dezembro, o comitê do partido lança o informativo do movimento emancipacionista: Libertação. Amílcar Cabral organiza a luta e continua a escrever 5 .

A cuidadosa edição epistolar de Amílcar Cabral, com a adição de importante acervo fotográfico e a impressão fac-símile de cinquenta e três cartas escolhidas desloca do espaço privado para o campo da história política o cenário e a trajetória de formação e práxis revolucionária de umas das expressões do marxismo negro. As cartas, que podem ser definidas como poéticas de amorosidades compartilhadas, não deixam de narrar experiências de racismo, africanidades e vontades criadoras numa África que se pretendia emancipada do fardo colonial. Assim, um "patrimônio privado", carregado de afetividades, foi possível ser disponível para um vasto público leitor graças ao projeto de edição coordenado pela historiadora Iva Maria Cabral, primeira filha de Amílcar Cabral e Maria Helena, pesquisadora da "história racial" em

\footnotetext{
${ }^{5}$ Quase a totalidade dos escritos políticos de Amílcar Cabral foi publicada numa primeira edição, em 1977, em dois volumes, sob a coordenação de Mário de Andrade, seu biógrafo angolano e também intelectual ativista das emancipações africanas, especialmente de Angola. Depois disso, a obra foi republicada. Ver: CABRAL, Amílcar. Unidade e luta: a arma da teoria. Vol. 1; Unidade e luta: a prática revolucionária. Vol. 2 (Obras Escolhidas). Praia: Fundação Amílcar Cabral, 2013.
} 
Cabo Verde e autora da tese de doutorado A Primeira Elite Colonial Atlântica: dos "homens honrados brancos" de Santiago à "nobreza da terra" - Final do século XV Início do século XVII (Praia: UCV, 2013). Antes do "Aqui me tens" - o corpus epistolar - uma primeira parte, constitutiva de "considerações, apresentações $e$ prefácios", converge para a escrita e o casal protagonista. Os editores, Márcia Souto e Filinto Elísio, na apresentação "Triunfar sobre a morte vulgar ou considerações acerca da edição do livro Cartas de Amílcar Cabral a Maria Helena: a outra face do homem", acertaram na metodologia de edição, ao proporem, em vez de anexos que se tornam irrelevantes, "acompanhar cada transcrição com seu respectivo original, de modo a propiciar ao leitor não só o acompanhamento, no calor da leitura, do texto manuscrito (o papel, a letra e os estados de alma, elementos que possam vir a revelar mais acerca do autor no momento da feitura da carta), mas também para facilitar alguma atenção especial que os leitores possam ter em relação a alguma passagem $e$ facilitar o contato mais próximo com o texto autógrafo" (p. 13).

Pedro Pires, companheiro do autor das missivas nas lutas de libertação e atual presidente da Fundação Amílcar Cabral, assina o prefácio "Convergência no tempo e nos propósitos" (p. 19-24) onde se surpreende pela ausência da correspondência de Maria Helena, "desconhecemos a plenitude das suas cartas e das suas respostas aos apelos e interpelações do Amílcar". Essa diluição da voz feminina nalgumas citações da escrita masculina não se coaduna com os avanços notáveis das teorias feministas desde que Maria Helena se tornou uma das primeiras engenheiras agrônomas formadas numa faculdade portuguesa. O olhar atento de Pedro Pires vê em "Lena" a confidente e depositária das ideias e reflexões de Amílcar Cabral, mas que, "por vezes, o diálogo ganhava a força de um monólogo em que martelava e repetia as ideias quase que se dirigindo a si próprio". Pires atenta para cinco momentos reveladores das cartas que permitem acompanhar a trajetória $e$ formação revolucionária do sujeito apaixonado. $\mathrm{O}$ primeiro foi o enfrentamento do racismo ao se relacionar com uma mulher branca. O segundo dizia respeito à questão ética das relações humanas e da política. O terceiro implicava a defesa da dignidade humana $e$ as responsabilidades sociais frente às injustiças e desigualdades econômicas. $\mathrm{O}$ quarto, talvez o mais pragmático, seria o "chamamento africano" como se fosse um destino traçado em lutar pela emancipação dos povos africanos, notadamente os da Guiné e de Cabo Verde. Por fim, o quinto, narrado na última carta, configura "o fim do ciclo da vida privada" e a consequente "partida para o desconhecido e o incerto" com uma pitada de fé na "vitória sobre o colonialismo".

A pesquisadora Inocência Mata, no ensaio prefacial, "As cartas de Amílcar a Maria Helena como documento expressivo na construção de uma narrativa coletiva" (p. 2733), defende a hipótese que as cartas formam "um duplo espaço biográfico" do emissor e da destinatária, ainda que estejam ausentes as "respostas físicas" de Maria Helena. A autora pontua que embora a função prevalecente nas cartas seja a "razão emotiva" o livro se constitui como "filigrana documentativa de um tempo ainda presente na memória coletiva, vale dizer, no caso, (trans)nacional (pelo menos GuinéBissau, Cabo Verde e Portugal) - e nisso consiste o interesse público e institucional deste acervo". Outra apresentação das cartas, "História em Dueto" (p. 37-40), assinada por Carlos Lopes, organizador do importante livro Desafios Contemporâneos da África: o legado de Amílcar Cabral (São Paulo: Editora da UNESP, 2012) e atual 
secretario executivo da comissão econômica das Nações Unidas em África, observa que desde a primeira carta, datada de 1946, aparece "uma personalidade vocacionada para fazer história". Lopes enfatiza um percurso, "indivíduo e sociedade", perceptivel no suporte carta, "documento afetivo", que presumivelmente seria o espaço para a "vivacidade poética" e o "arrebatamento amoroso". Lopes também lamenta ficar "sem acesso às cartas de Helena", mas defende que a "história em dueto" seria também aquela protagonizada por Maria Helena, "a de Amílcar e a de África".

Bem, já que decidimos apresentar a "primeira parte" ao final desta resenha, voltaremos, para concluir, à carta do dia 21 de outubro de 1946, a segunda do corpus, na qual Cabral escreve para uma já notada colega de faculdade, ela então com 19 anos e, ele, recém-chegado a Lisboa, com 22 anos: "Bem: já vou longe... Retorno, e respeito o pouco tempo de que dispóe, cara colega. A propósito do tempo de que dispõe: eu queria escrever no princípio: Leia quando tiver tempo, mas só o faço no fim. Quantas vezes, na vida, o fim não é o princípio?” (21 out. 1946, p. 47).

Aqui me tens! Do privado para o público. Entretanto, segundo as teorias feministas, o privado é público e o pessoal é político. Então, além do que expressamos como documentos afetivos, esse conjunto de cartas não seria também um patrimônio?

\section{$\operatorname{soc} 2$}

Resenha recebida em 15 abr. 2017.

Aprovada em 06 mai. 2017. 